\title{
Correction to: Size is not everything: differing activity and foraging patterns between the sexes in a monomorphic mammal
}

\author{
Hanna Kavli Lodberg-Holm ${ }^{1}$ (D) S. M. J. G. Steyaert ${ }^{1,2} \cdot$ S. Reinhardt ${ }^{1} \cdot$ F. Rosell ${ }^{1}$
}

Published online: 17 April 2021

๑) Springer-Verlag GmbH Germany, part of Springer Nature 2021

\section{Correction to: Behavioral Ecology and Sociobiology}

https://doi.org/10.1007/s00265-021-03010-7

After publication of this paper, it was found out the corresponding authors name was mentioned twice in the author group. The correct author name is: Hanna Kavli Lodberg-Holm.

The original article has been corrected.

Publisher's Note Springer Nature remains neutral with regard to jurisdictional claims in published maps and institutional affiliations.

The original article can be found online at https://doi.org/10.1007/ s00265-021-03010-7.

\footnotetext{
Hanna Kavli Lodberg-Holm hal@usn.no

1 Faculty of Technology, Natural Sciences and Maritime Sciences, Department of Natural Sciences and Environmental Health, University of South-Eastern Norway, Bø i Telemark, Norway

2 Faculty of Biosciences and Aquaculture, Nord University, NO-7711 Steinkjer, Norway
} 